\title{
La puesta en escena en el aula de enseñanza del español como lengua extranjera (ELE)
}

\section{The staging in the Spanish as a Foreign Language (sFL) classroom}

María del Socorro Gutiérrez Martínez ${ }^{1}$

Freie Universität Berlin

\begin{abstract}
Resumen: Este trabajo propone el uso del espacio vacío para el aprendizaje del español como lengua extranjera (ELE), tomando como marco teórico las ideas de Peter Brook (2014) y la puesta en escena en la clase de ELE como metodología y recurso pedagógico. Se muestra en este texto el trabajo de campo llevado a cabo en una presentación en el aula, cómo se utilizaron elementos y objetos de uso habitual en la clase, la puesta en escena y el arte de las expresiones oral, visual, corporal y auditiva, que componen las perspectivas del trabajo del Marco Común Europeo de Referencia para las lenguas: aprendizaje, enseñanza y evaluación (MCER). Se propone el empleo de aquellos elementos que la escenificación proporciona y que se tienen al alcance en el aula. Se plantea la investigación-acción, que muestra las posibilidades pedagógicas que pueden mejorar la atmósfera en el grupo, el desarrollo de la afectividad, la concentración, la gramática en acción y el aprendizaje colaborativo en un ámbito intercultural por medio de la puesta en escena y de la utilización del espacio siguiendo los postulados de Brook.
\end{abstract}

Palabras clave: teatro-espacio-vacío, artes escénicas, lenguaje corporal, enseñanza de ELE

Abstract: This paper analyzes and presents the use of empty space to teach Spanish as a foreign language (ELE). It further addresses how setting the stage for an ELE course serves as a methodological

1 Doctora en Filosofía por la Freie Universität Berlin. Ha sido profesora en la Universität Potsdam y en diversas universidades en Asia. Tiene trabajos publicados sobre cinematografía y literatura, cartografía de la memoria, entre la historia y la ficción, periodismo cultural y reseñas musicales. Ha realizado guiones y reportajes para la Radio Naciones Unidas (onU), sobre derechos humanos, explotación y opresión de las mujeres y los pueblos indígenas. Actualmente realiza una investigación sobre población china en América en Das Iberoamerikanisches Institut, en Berlín. 
and teaching resource, drawing on Peter Brook's ideas as theoretical framework. This text presents field work in an actual classroom presentation, the use of elements and objects common to a classroom setting, how the stage is set, as well as the art of oral, visual, corporal and auditory expressions, all components of the Common European Framework of Reference for Languages: learning, teaching and assessment (CEFR). It is suggested that, in setting the stage, teachers only make use of those elements that are readily available in a classroom. The research-action demonstrates the pedagogical possibilities that can improve the atmosphere in the group, the development of affectivity, concentration, grammar in action and collaborative learning in an intercultural environment through staging and the use of space in line with Peter Brook.

Keywords: empty space in theater, performing arts, body language, SFL teaching.

\section{INTRODUCCIÓN}

Puedo tomar cualquier espacio vacío y llamarlo un escenario

P. Brook

Este texto es el resultado de la praxis-investigación de un proyecto llevado a cabo en universidades de diferentes países en Asia. En estas instituciones se ha planteado el uso del espacio propuesto por Peter Brook (2014) y de diferentes elementos teatrales como método didáctico en el aprendizaje de una lengua extranjera en un contexto formal de aula, en este caso, la enseñanza del español como lengua extranjera (ELE). El presente trabajo no pretende minimizar la tradición teatral ni su práctica independiente como asignatura formal, ni hacer del arte teatral un elemento rudimentario (Fleming y Byram, 2001: 155); se trata de analizar las necesidades de un grupo de estudiantes de lengua en un contexto intercultural (Morgan, 2001), en el cual es posible que lo generacional coincida con un proceso de innovación y multiplicación de espacios donde se utilizan medios de comunicación digitales propios de la época, como teléfonos celulares, aplicaciones como Signal, Telegram, Instagram, WeChat, Weibo, TikTok, entre otros medios usados por muchos jóvenes. Se intenta con esta investigación contribuir a ampliar el uso de la puesta en escena en las clases de elE en diferentes niveles, como lo ha tratado Berber Irabien (1998), quien comparte la idea de Maley y Duff (1982) sobre la agilidad que demuestra el 
estudiantado en las representaciones propias y no (necesariamente) en las de autores destacados.

La hipótesis de la que parte este trabajo es que, por medio del desarrollo de la representación teatral, el alumnado de los niveles A1-A2 y B1-B2 de ELE, puede alcanzar un nivel alto de competencia en contenidos culturales y un léxico adecuado para dichos niveles. La investigación parte de la consideración de que el estudio de una lengua a través de la puesta en escena - particularmente siguiendo el concepto de espacio vacío de Peter Brook (2014)-, permite mejorar, entre muchos otros aspectos, la fluidez, la precisión, la adquisición, la recuperación inmediata y la retención de lo aprendido.

El objetivo general de este trabajo es presentar las características de una herramienta teatral que pueda apoyar a los docentes en el proceso de enseñanza-aprendizaje de la lengua, así como lograr que vean como recurso creativo la propia aula y puedan dar respuesta a los conflictos y a las dificultades (gramaticales). Como objetivo específico se propone fomentar la competencia comunicativa de alumnas y alumnos por medio de la puesta en escena y su realización práctico-técnica en el aula.

Esta propuesta se ha llevado a la práctica con 148 alumnos (en diferentes grupos) de edades comprendidas entre los 17 y 21 años; el 30, 41\% lo conformaban estudiantes varones y el 69,59\% estudiantes del género femenino (Figuras 1 y 2). Los discentes participaron en un curso de 64 horas (4 horas a la semana durante 16 semanas cada grupo). El curso posterior, después de las vacaciones, fue de 80 horas (cubiertas en 20 semanas, entre 4 y 6 horas cada clase-equipo); los grupos fueron diversos y acudieron a clase dos o tres veces por semana. Estos datos se señalan para dar cuenta del progreso en un periodo determinado, como se verá más adelante.

División por género

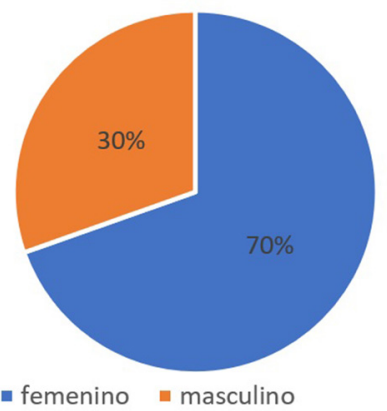

Figura 1. Participación predominante. Elaboración propia.
Edades de los participantes

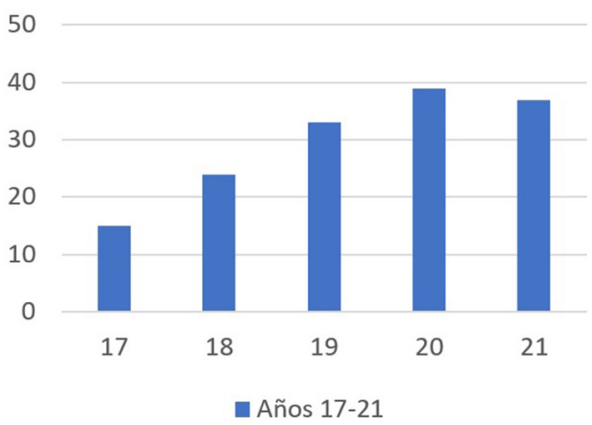

Figura 2. Edad promedio estudiantil. Elaboración propia. 


\section{ELEMENTOS TEATRALES COMO MÉTODO DIDÁCTICO}

\subsection{La enseñanza y el teatro}

Para Jackson (2013), el movimiento crítico británico de los años sesenta llevó a la organización de lo que sería conocido como Theatre in Education (TIE) en Belgrado en 1965. Los autores y las técnicas que Balme (2008: 22) revisa (Stanislavsky: involvement; Brecht y Meyerhold: detachment) y Grotowski: selfrenunciation) dieron lo mejor de sus propuestas, pero en Inglaterra, en los años setenta, hubo una etapa para la comunicación y el auge de la enseñanza a través del teatro. Maley y Duff (1978), por ejemplo, diseñaron actividades para profesores de idiomas en esa década. Posteriormente, Schewe (1993) pretende sentar las bases metodológicas de la pedagogía dramática en el aprendizaje y la enseñanza. Desde su experiencia y teoría, el autor hace un reconocimiento a la propuesta pionera de Harriet Finlay-Johnson acerca de que debían adaptarse dramáticamente todas las asignaturas de un plan de estudios. Finlay-Johnson estaba convencida de que podía lograrse. En otras palabras, puede observarse que la organización planteada por Jackson (1993), Maley y Duff (1978) y Schewe (1993) se refiere a las formas sistematizadas que permiten identificar procedimientos pedagógicos. Para llevarlos a cabo sería necesario contemplar al sujeto como un todo en movimiento. Al respecto, Schewe cita un proverbio chino: "Si lo hago, lo comprendo; si lo actúo no lo olvidaré" (Schewe, 1993: 1). La lengua extranjera se convierte en un idioma de acción y herramienta que contribuye a cumplir objetivos en un contexto significativo real de comunicación. Para Peter Brook lo significativo es de vital importancia: "En la vida cotidiana, 'si' es una ficción; en el teatro, 'si' es un experimento" (Brook, 2014: 189).

La vinculación de la enseñanza de idiomas y la dramaturgia contempla todos los sentidos y los sonidos a nuestro alrededor, es un aprendizaje físico hecho posible por el teatro $y$, al mismo tiempo, ensayado; es un espacio protegido en las posibilidades de acción.

En la enseñanza de idiomas deben ser considerados los contextos socioculturales y transculturales - véanse las acotaciones de Risager (2001) más adelante-, de tal manera que las competencias lingüísticas (gramatical, discursiva, pragmática, sociocultural y la estratégica de comunicación y aprendizaje) y las destrezas (escuchar, hablar, leer, escribir, mediar e interactuar) (Alcón Soler, 2002: 87-88), al intercambiar un input/output, propicien que este binomio se relacione con el entorno en el que se vive. Debe haber una 
propuesta lúdica, actual y de interés en el entorno en el que se trabaja y se aprende. Por lo tanto, la sociolingüística juega un papel importante y la puesta en escena proporciona una visión para reinterpretar nuestra idea del mundo y comunicarla. Eso incluye el manejo de las tecnologías de la información y la comunicación (TIC), siempre que sea posible.

\subsection{La enseñanza del español y el teatro como herramienta didáctica}

El teatro como elemento didáctico es una propuesta pedagógica múltiple en su forma y contenido que se enfrenta a diferentes discusiones. Los antecedentes teatrales (Berber, 1998) tienden a la representación de obras formales; sin embargo, la clase de ele puede activar la destreza de la escritura por parte del estudiantado al propiciar la creación de sus propios diálogos de manera directa y de acuerdo con sus necesidades de comunicación. Las alumnas y alumnos podrán percatarse de aquellos elementos que les facilitarán la comunicación; encontrarán la motivación necesaria para integrar palabras de forma adecuada, poniendo en práctica lo aprendido o buscarán cubrir aquellas necesidades gramaticales que los motivará a querer saber más e identificarán que la aplicación de esos elementos en un diálogo para ser escenificado lo demandará.

Las dificultades de entablar una conversación con naturalidad (AlonsoCortés, 1998), por ejemplo, o la imposibilidad de intervenir en una conversación al no tener el uso de la palabra que ofrecen la etiqueta y la cortesía de los hablantes en su lengua de origen, podrán ser superados dentro de una atmósfera afectiva (Cano Gines, 1996). Por consiguiente, al enfrentarse a diversas situaciones comunicativas, los discentes podrán utilizar elementos que en su propia lengua no tienen un carácter relevante para la comunicación, como puede ser el uso de artículos determinados para los estudiantes chinos (Hui-Chuan, 1998).

En el Marco Común Europeo de Referencia (MCER) se señalan algunas especificaciones sobre el "uso lúdico de la lengua como propósito comunicativo" (Consejo de Europa, 2002: 87), así como acerca del lenguaje corporal y el acercamiento a una escenificación (Brook, 2014: 59-60). Dentro de esa línea se inscribe la temática de las actividades de proceso que señala Peter Brook en la puesta en escena: "la representación es lo que alega ser: hacedora de presente" (2014: 187). Contribuye a romper con la disputa drama versus teatro como proceso y producto. En la representación teatral, la interacción está presente todo el tiempo y no puede (no debe) mantenerse aislada. Brook lo manifiesta en las variaciones denominadas teatro mortal, teatro sagrado, teatro tosco y 
teatro inmediato. Nos dejaremos guiar por este último y recurriremos a los clásicos para respaldar la presente propuesta. Aristóteles, en la Poética, define la tragedia como "la imitación no de las personas, sino de la acción y de la realidad de la vida" (Aristóteles, 1991:21, traducción propia). Un uso, en el caso especial del drama, que sirve para nuestro propósito. Cabe recordar que la lengua se define como un mecanismo de "interacción-mediación" (Consejo de Europa, 2002: 14) para la enseñanza.

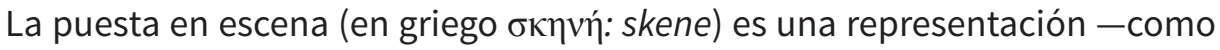
la entiende Brook (2014) en su significado de la palabra en la lengua francesa: représentation $\leftrightarrow$ interpretación-, el aquí y el ahora que se exploran en esta propuesta para lograr formular las posibilidades que se tienen en el aula de ELE $y$, de esta forma, favorecer el desarrollo de las competencias comunicativas en un marco intercultural (Risager, 2001) más globalizado, en donde no hay activos ni pasivos en los términos tradicionales. Asimismo, se trata de un tipo de teatro, a la manera de Brook (2014), que juega un rol en la comunicación. Anna Corral (2013) señala este rol como receptor $\leftrightarrow$ espectador, participante $\leftrightarrow$ actor, como las prácticas generales de la acción. Sin embargo, estos roles, si bien han ido cambiando en la discusión y la acción, se presentan con características diversas en la clase de ELE y tienen que ver con el proceso creativo (Duchamp, 1968) y sus Teilnehmer/Teilnehmerin, utilisateur/utilisatrice implicados. Dialogar sobre el espacio vacío y la puesta en escena es una necesidad no solamente para el aula, sino que representa una demanda de investigación sobre la creación y el escenario de representación, a fin de comprender lo que la cultura significa en el ámbito de la enseñanza de lenguas extranjeras, ya que no son elementos ajenos. Marcel Duchamp estaba convencido de que "el cuadro existe cuando lo miran. El cuadro lo crean cuando lo miran" (1968: 63-65), y Octavio Paz lo confirma citando sus palabras: "el espectador hace al cuadro" (Paz, 1968: 57). Para Paz, Duchamp no da cuenta de todo el proceso creador; sin embargo, continúa el autor: "una obra es una máquina de significar. En este sentido la idea de Duchamp no es enteramente falsa: el cuadro depende del espectador, porque solo él puede poner en movimiento el aparato de signos que es toda la obra" (1968: 58). Peter Brook (2014) señala que basta con que alguien mire para que inicie el cruce de acciones escenificadoras.

El teatro como método de enseñanza presenta la oportunidad de que sean los alumnos y las alumnas quienes trabajen con la puesta en escena y creen a sus personajes a partir de algún tema que les interese (o en función de alguna materia que estén cursando paralelamente: historia de España, de América Latina, literatura, etcétera). Les ayudará, por ejemplo, a planear un Erasmus; 
potenciarán su creatividad para hablar con un tercero, consigo mismos/as, o con ambos a la vez, con mayor entusiasmo.

Las alumnas/os que observan a sus compañeras/os podrán hacer una evaluación, a través de lo que están presenciando (Figura 3), de las actitudes, del léxico y del vocabulario que la escena demanda (¿Olvidarían encender las lámparas o pedirle a alguien que las encienda y las apague al salir?, ¿qué recursos de la lengua-cultura podrían utilizar en esta situación?). Varios estudiantes que participaron en estas puestas en escena manifestaron que se habían dado cuenta de que les faltaban algunos conectores para expresarse. Habían descubierto una necesidad en la cual iban a trabajar para la siguiente clase. Los enunciados que utilizaron no requirieron una memorización tradicional (pero no se desecha, según la utilidad y costumbre del país - somos huéspedes en otra cultura-).

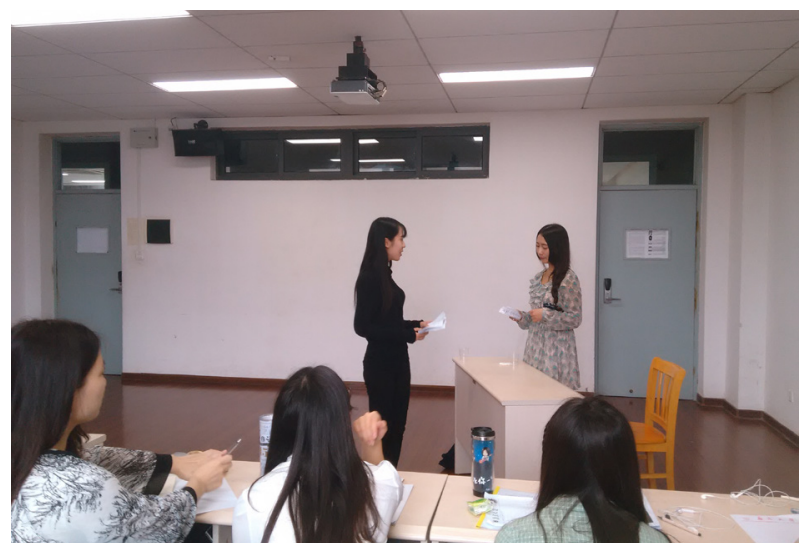

Figura 3. Alumnas observan y evalúan. Elaboración propia.

El estudiantado que colabora en una representación tiende a desarrollar diversas destrezas. Mientras transcurre la escena escuchan, modifican sus propios discursos cuando detectan errores en los participantes que les preceden; son, asimismo, sujetos de autoevaluación, en donde la mirada recreativa de sus compañeras/os combina corrección, escritura y dicción, y ponen en marcha el lenguaje verbal y el no verbal (quinesia, proxemia). No tienen un rol pasivo, como el del público tradicional; por el contrario, los estudiantes desarrollan un sentido cooperativo y sociocultural de trabajo, hacen uso de diversas estrategias (aprendidas y/o propias) para verterlas en el espacio de trabajo y las adaptan a los elementos de su entorno.

El foco de los diferentes ejercicios gramaticales, por ejemplo, ayudará a trabajar el sentido de los enunciados, centrándose en el aprendiz de forma 
interactiva. Al mismo tiempo, favorecerá la atención al significado. Esto lo desarrollan los estudiantes de la clase de ele cuando se enfrentan a la puesta en escena en un lugar que generalmente no se usa como un escenario convencional. Para representar una escena teatral es necesario cambiar el concepto de dónde se puede trabajar, buscar una forma de acción en un "teatro inmediato", según Brook (2014).

Manfred Schewe está convencido de que todas las destrezas pueden estimularse en una recreación, integradas por medio del drama en un contexto con situaciones reales.

Los ejercicios comunicativos, como se entiende aquí, pueden ser vistos como
parte central de la dramaturgia pedagógica en las clases de lengua extranjera.
Los ensayos lingüístico-formales no están en primer plano (aunque están
integrados y acompañan), sino que se concentran en la elaboración y el
contenido del mensaje. La clase de lenguas extranjeras con pedagogía teatral
es una enseñanza de lenguas extranjeras comunicativa, porque las formas de
trabajo y de práctica utilizadas en ella persiguen el mismo fin (Schewe, 1993: 85,
traducción propia).

En este sentido, la dramaturgia pedagógica y la clase con propósitos comunicativos tienen la misma finalidad; como lo ha señalado Esch (1988), son parte de los objetivos de enseñanza y necesidades de mejoramiento expresivo.

\subsection{El lenguaje corporal y la puesta en escena en el aula}

La enseñanza, sin movimiento, no presta la atención debida al lenguaje corporal en el aula y dificulta el aprendizaje integral de un idioma. Jenson y Hermer (2011) coinciden con Bateson, quien estaba convencido del papel que juega el cuerpo, justificado por el ejemplo del metadiálogo (Batenson, 1972: 13) sobre el aprendizaje de la lengua francesa y el lenguaje corporal. Bateson, Jenson y Hermer reflexionan sobre su experiencia: "esta lengua, sin cuerpo, se olvida desgraciadamente en poco tiempo" (Jenson y Hermer, 2011: 183).

Los gestos y la mímica son los centros de expresión de la lengua. El lenguaje corporal es una muestra de nuestra personalidad, de la correspondencia con el idioma y la cultura de las civilizaciones. El arte es una consecuencia de la exploración sobre la vida y las personas, la forma de contar una historia y cómo lo expresa el cuerpo es la base fundamental cuando se aprende un idioma. "Una palabra no comienza como palabra, sino que es un producto final que se inicia como impulso estimulado por la actitud y conducta que dicta la necesidad de expresión" (Brook, 2014: 23). La experiencia teatral, como asignatura extracurricular, es viable si se trabaja de forma independiente, con 
su propio tiempo y duración. La puesta en escena ofrece diversidad, aprovecha todos los sitios que regularmente tienen quienes se dedican a la enseñanza $y$, por supuesto, aprovecha la elección acertada del libro de texto. En nuestro caso, fue muy importante que estuviera enfocado en el estudiantado chino, por niveles, y basado en las funciones comunicativas, el contenido gramatical, las diferencias culturales, el vocabulario adecuado para los niveles A1-B2 (con traducción al chino mandarín). La combinación de los libros de textos y la escenificación teatral da como resultado un aprovechamiento notable, como se puede advertir en la Figura 4, donde resalta la tendencia hacia el mejoramiento del aprendizaje. En los meses correspondientes a las vacaciones, la curva de provecho tuvo un descenso en todos los niveles, lo cual se revirtió posteriormente.
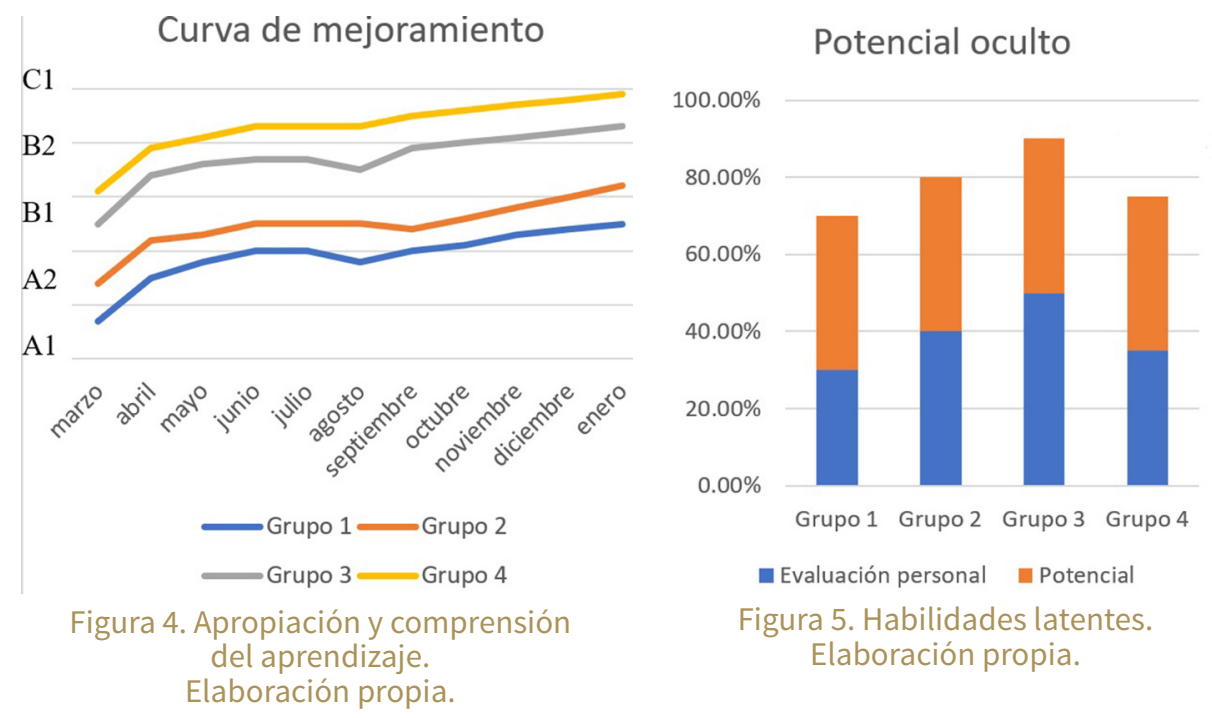

El interés en motivar el aprendizaje de la lengua y su fortalecimiento con la puesta en escena como principal elemento didáctico, aumentaron la participación al regresar a clases (Figura 5). El alumnado, al ver sus habilidades potenciadas, desarrolló una motivación personal; fueron las y los estudiantes quienes buscaban en los contenidos gramaticales y en su vocabulario lo que necesitaban para comunicarse; eso incluía su desplazamiento por el aula: su escenario. Algunos estudiantes lograban comunicar con movimientos expresivos lo que deseaban, preparaban su diálogo, la conjugación de los 
verbos y las frases que deseaban decir. Habían adquirido mayor seguridad y confianza en sí mismos.

El lenguaje corporal es inherente al ser humano. No basta con "señalar con el dedo, la mano, la mirada", como lo describe el mCER (Consejo de Europa, 2002: 86-87) o recurrir a la "demostración con deícticos (Yo cojo este y lo sujeto aquil)" y a las "acciones observables con claridad (¡No hagas eso!)".

Los criterios para la puesta en escena en la clase de ele tienen un fin pedagógico, pretenden acercar el trabajo escénico e incrementar el aprendizaje a través del arte y la autonomía, con especial atención al lenguaje corporal a través de la observación.

Con esa asistencia, la de los ojos, deseos, goce y concentración, la repetición se convierte en representación. Entonces esta última palabra deja de separar al actor del público, al espectáculo del espectador; los abarca, y lo que es presente para uno lo es asimismo para el otro [...] El público asiste al actor y, al mismo tiempo, los espectadores reciben asistencia desde el escenario (Brook, 2014: 188).

La profesora/el profesor asiste al estudiantado como un/a director/a de teatro lo haría; el resto mira la escena mientras le corresponde su turno: asisten a un acto (Figura 6).

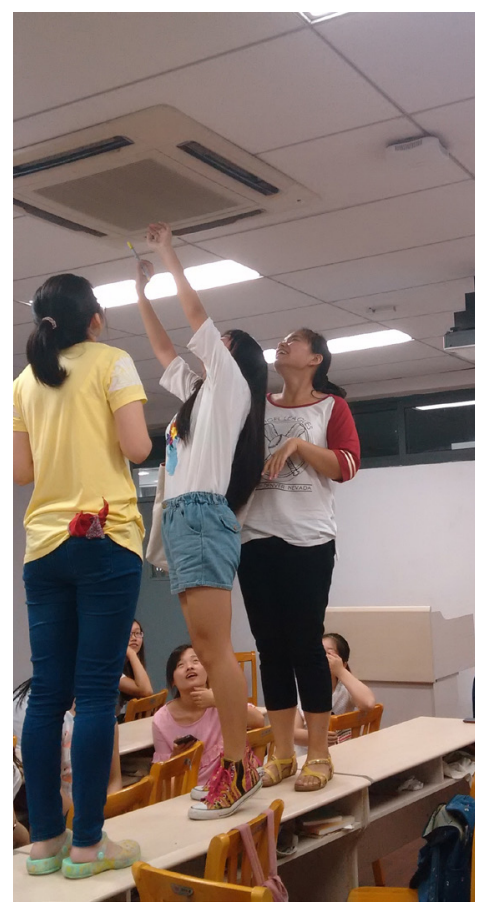

Figura 6. Alumnas ELE: la experta (actriz-alumna) ha sido llamada para hacer reparaciones. Elaboración propia. 
Las prácticas escénicas apoyarán entonces el aprendizaje. Alfonso de Toro señala la repetición y su relación con que "el artista moderno deba enfrentarse al fenómeno de la repetición para estudiar la posibilidad de conservar el saber y la memoria cultural en un medio por principio efímero" (2014: 69). Esta relación cambia cada día con los ensayos. Los jóvenes actores del aula de ele recrean sus propias dinámicas de vida, preocupaciones o alegrías. Los discentes ponen en práctica diversos recursos de la lengua en un ambiente agradable y toman conciencia del lenguaje corporal.

Para Peter Brook "antiguamente los cómicos ambulantes adaptaban su trabajo a los distintos lugares; en la actualidad, las elaboradas puestas en escena carecen de esa flexibilidad" (Brook, 2014: 137). Según el autor, la pizarra del teatro (aula de clases para los profesores/as) se borra constantemente. Esto hace que los directores/as inventen cada día, al igual que los profesores/as inician sus clases cada día bajo circunstancias diferentes a lo planificado. Por ello buscan un método, nuevas ideas que apoyen en el trabajo en el aula.

\section{LA PUESTA EN ESCENA Y SUS CARACTERÍSTICAS}

\subsection{El espacio vacío de Peter Brook y su funcionamiento en las clases de ELE}

Peter Brook emplea su propio ejemplo para definir the empty space y su significado: "Puedo tomar cualquier espacio vacío y llamarlo un escenario desnudo. Un hombre camina por la habitación mientras otro observa; eso es todo lo que se necesita para la acción del teatro" (Brook, 2014: 19). Maley y Duff sugieren, con respecto al espacio, cambiarse a otro salón de clases o "cuarto", algo que la mayoría de las veces no es posible. Los autores sugieren desplazar los objetos hacia otro sitio, pero el uso de las mesas puede tener otra utilidad, como se hizo en las aulas de algunas universidades en Asia con el apoyo del estudiantado: un escritorio colocado sobre una mesa podría formar la barra de una cafetería y tener suficiente altura para una conversación entre estudiantes.

Existen muchos elementos que pasan desapercibidos, hay que volver a mirar con bríos más creativos. Una sala, un aula, pueden convertirse en magníficos escenarios. Dos puertas de entrada proporcionan el espacio ideal para la puesta en escena. Las mesas y las sillas pueden ser las butacas de un teatro o ser ellas mismas, simplemente. El clásico mutis y la duración de la escena los marcan la entrada y salida de las/los estudiantes en una representación. El 
objetivo es usar todas las características de las aulas en beneficio de la acción correspondiente, como se puede apreciar en la Figura 7.

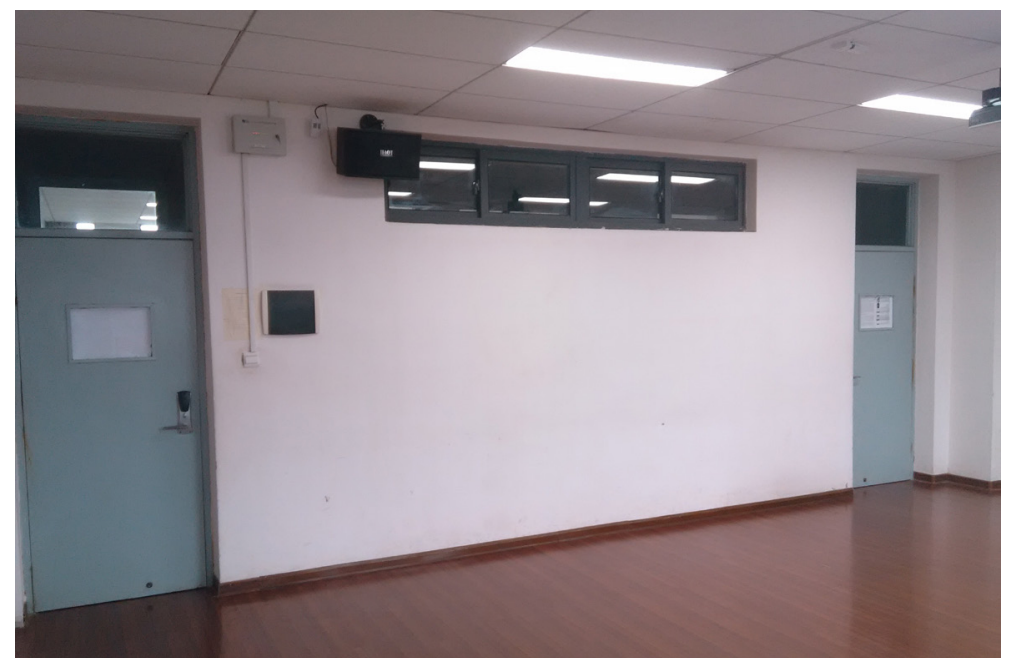

Figura 7. Vista lateral. Interiores. Aula universitaria.

Elaboración propia.

La idea es retomar el teatro en su forma elemental y ampliar las habilidades de la imaginación, la concentración y la comunicación (Brook, 2014), que no solo apoyan la adquisición del lenguaje, sino que hacen ver al estudiante cuánto sabe de una lengua y su aplicación en la vida real de manera significativa. Por ejemplo, el uso de los verbos adecuados es ahora una necesidad y no un ejercicio de memoria. La cortesía y los turnos para ceder la palabra o continuar el diálogo son una respuesta a la situación.

La pedagogía teatral y el espacio vacío de Peter Brook son un terreno especial que vincula el arte con una asignatura en la práctica: trabajar en el aula (no se necesita ir a otro lado) revitaliza nuestras áreas de trabajo dándoles un uso; interactúan con la enseñanza, para que alumnas y alumnos adquieran elementos que les permitan comunicarse y moverse en diferentes contextos. Pueden ampliar su círculo de conocidos y su vocabulario; por ejemplo, con las variedades del español, una mala decodificación intercultural puede llevar a malentendidos e incluso, en el caso de los negocios, podría obstruir el cierre de un contrato con una empresa o un malentendido en una cafetería.

La práctica del teatro para la adquisición de una lengua no necesariamente debe derivar en una actuación "formal". Los estudiantes necesitan un resultado motivador inmediato que no intervenga con otras asignaturas (en el sistema escolarizado), o que les permita invertir el tiempo necesario sin que eso sea una carga de trabajo extra. Así que realizar una escena o una tarea final (que puede 
ser la representación), se debe planificar con tiempo adecuado y dar lectura al estado de ánimo del grupo. Observar y escuchar las necesidades del grupo, dependiendo del país, la ciudad o la comunidad donde se encuentren, resulta vital, pues los códigos culturales propios no deben interferir para comprender o juzgar a otra sociedad y sus estilos de aprendizaje. Si prefieren memorizar, porque así es su sistema, se debe respetar. Las profesoras y profesores en el extranjero son huéspedes y los estudiantes que viajan para aprender un idioma a otro país tienen su propio sistema de cortesía y aprendizaje, que hay que considerar en el sistema de enseñanza. El desarrollo de la competencia intercultural en el aula corresponde también al personal académico, no solo al estudiantado.

Los entornos culturales, según Risager (2001), aportan conocimientos que, para los intereses de los jóvenes, son decisivos en el desarrollo del proceso de enseñanza-aprendizaje. El placer de aprender es algo que debe reflejarse en el rendimiento y, en este sentido, la educación teatral es una fuente de inspiración y un método de trabajo.

\subsubsection{Rompiendo los mitos}

El teatro pedagógico es un terreno que no deja de tener detractores; sin embargo, la puesta en escena en el aula determina a quienes intervienen, pues experimentan cambios al compartir una situación definida, concreta, aun en la legendaria China, donde la gramática tradicional y la memorización son la regla. Los estudiantes aprenden, no quepa duda. Jenson y Hermer señalan las ventajas del teatro, porque los discentes "retienen con mayor facilidad" (2001: 184). Los estudiantes escucharán con atención a las/los primeras/os participantes, en el ejercicio harán de "público" y serán "actores/actrices" a su vez. Esto se ha manifestado en la escena profesional con bastante éxito, como señala Peter Brook: "el lector no tenía que concentrarse para tomar conciencia desí mismo, para preguntarse si empleaba la entonación adecuada. Sabía que el público deseaba escuchar y quería dejarle escuchar: las imágenes encontraron su propio nivel y guiaron su voz inconscientemente hacia el apropiado volumen y tono" (Brook, 2014: 38).

Los usuarios pueden, a través de la puesta en escena, aumentar diversas competencias en el proceso de comunicación requerido por el MCER (Consejo de Europa, 2002) para los exámenes en institutos o universidades, pero también para conocer y disfrutar otras culturas y al mismo tiempo reflexionar sobre cómo evaluamos y desde qué perspectiva, para que sean, de acuerdo con el MCER, "más apropiados y viables en la cultura pedagógica de su sistema" (Consejo 
de Europa, 2002: 193). La propuesta de la representación escénica como un instrumento importante en la enseñanza de ele podría ser parte de una demanda de profesionales más especializados, porque va en aumento la necesidad económica de aprender un idioma que es hablado por más de 495 millones de personas. Esto se confirma si observamos el estudio realizado por Sandra Nißl (2011: 156), en el cual señalaba que el español ocupaba el quinto lugar entre las lenguas más habladas del mundo, lo cual demandaba una inversión para fortalecerlo en la Comunidad Europea. El aspecto teatral del Plan Curricular del Instituto Cervantes (PCIC) para los primeros cuatro niveles del aprendizaje de ELE ocupa un espacio curricular (2006: 542) que podría asumir otras propuestas, pues en el informe realizado ocho años después por Fernández Vítores (2019: 15) se posicionaba al idioma español en el segundo sitio, por detrás del chino "por el número de hablantes". Rod Ellis (1997) ya mencionaba la importancia de la investigación en el aprendizaje de un segundo idioma y se preguntaba sobre la aportación que brinda a los profesores. El trabajo de Fernández Vítores marca el camino recorrido por el idioma español.

Se trata de una lengua global que cada día tiene mayor importancia en el mundo de los negocios (Nißl, 2011), por ejemplo, un ambiente en el que se necesita hacer uso del lenguaje de la diplomacia (hay que tener en cuenta que diversas universidades en Asia tienen un particular interés en América Latina) y, por ende, debe ser intercultural.

\footnotetext{
El enfoque transcultural se fija en la vida de los individuos y los grupos en entornos caracterizados por la complejidad cultural y lingüística en menor o mayor grado: las emisoras de televisión, la calle, la ciudad, el aula multicultural, el supermercado: situaciones en [las] que se utiliza la lengua objeto de estudio, pero de tal manera que los estudiantes llegan a tener conciencia del uso de otros idiomas (Risager, 2001: 248).
}

La interculturalidad nos permite observar las estructuras sociales en las que el lenguaje corporal juega un papel muy importante, así como los signos que emiten nuestras manos y nuestros ojos; esto se puede comprobar y mejorar en el aula.

\section{LA EXPERIENCIA TEATRAL EN EL AULA}

La primera parte práctica comenzó en el Colegio de Lenguas Extranjeras de una universidad en Asia con jóvenes adolescentes de ambos sexos (nivel A1-A2). La puesta en escena fue un proyecto (no de forma oficial o institucional) que se puso en marcha en el aula para fomentar la competencia comunicativa entre los estudiantes. Se les invitó a recrear una historia y a compartir sus creaciones. 
La modalidad de video-drama, con los/las alumnos/as de segundo curso (nivel B1-B2) estuvo representada por la adaptación escénica de Chac Mool de Carlos Fuentes (Figuras 8 y 9). La filmación tenía subtítulos en español para el ejercicio de lectura (en el momento de su exhibición); además, se planificaron actividades para el desarrollo de la escritura, la competencia comunicativa y el lenguaje corporal.

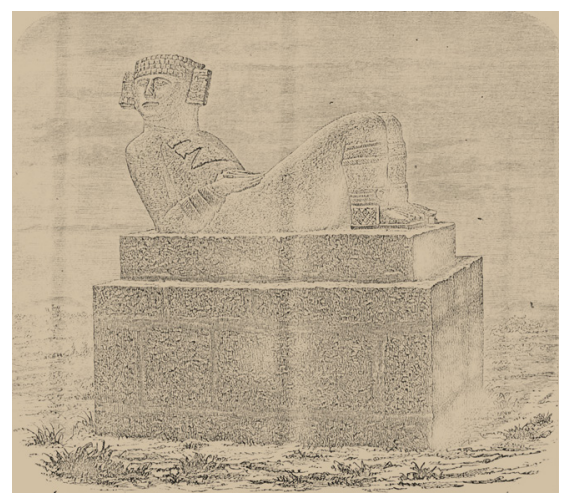

Figura 8. Maler, T. (Ed.) 1879 (http://resolver.iai.spk-berlin.de/ IAI00006A6E00000000)

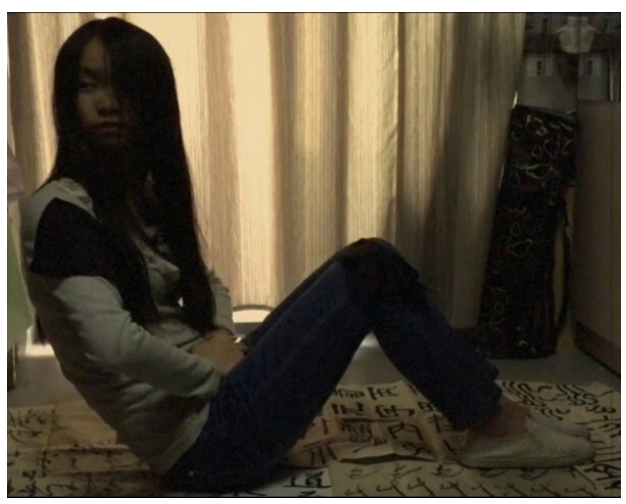

Figura 9. Alumna-Chac Mool en el sótano universitario.

Elaboración propia.

Redactar un texto y escenificarlo tiene grandes ventajas. En primer lugar, permite el acceso a la información con alto contenido gramatical de forma explícita. Las preguntas sobre el qué, quién, cuándo, dónde, cómo y por qué pueden llegar a ser muy útiles. En segundo lugar, apoyarse en un guion mejora la destreza de la escritura. Con el apoyo de la tecnología se puede leer en pantalla y, por ejemplo, aclarar cualquier conjugación verbal al instante. En el MCER se invita a "utilizar las nuevas tecnologías" (Consejo de Europa, 2002: 73), pues se sabe que los estudiantes practican con la tecnología que está a su alcance como algo cotidiano y estimulan su competencia lectora. Para los profesionales de la comunicación esto es muy claro: "estamos creando una conexión emocional con la tecnología de la generación de hoy, resaltando los nuevos canales habituales para las citas modernas" (Crespo, 2015: 8). La clase de ELE tiene que ser activa, formar parte del panorama cultural del alumnado (incluso si las condiciones son precarias). La publicidad, por ejemplo, tiene un fuerte impacto en la sociedad, y no puede ignorarse la homogeneización cultural que aborda Sarlo al señalar que "los barrios urbanos" y los "barrios audiovisuales" (1994: 14) tienen que ver con la presencia de la tecnología.

En el aula, la dinámica de trabajo y de comunicación ha sido preparada en función del usuario general, pero también puede funcionar para el usuario experto. El trabajo puede ser individual, poniendo atención en las inteligencias múltiples (Gardner, 2006), e involucrar al resto del grupo, mostrando a la vez 
un alto grado de autonomía. En la introducción de la propuesta se presentó la oportunidad de crear personajes basados en un tema que les interesara o relacionado con alguna materia escolar que estuvieran cursando en ese momento. En este caso, el estudiantado aportó su creatividad. En la representación, ellos debían saber o preguntarse si al entrar en un escenarioaula con la luz apagada deberían encenderla; exactamente como si estuviesen en una habitación propia, en un apartamento, usar la lógica de una situación real. La escenificación representa también lo que Villegas enfatiza al señalar que "la luz funciona como la guía de la mirada del espectador" (2009: 11). Frente a estas situaciones, el estudiantado es expuesto a interrogantes como las siguientes: ¿usarán las reglas de cortesía?; ¿saludarán?; ¿invitarán a tomar asiento a quien los/las visita?; ¿qué harían si fueran a un museo? ¿cómo sería su movimiento corporal?; ¿cómo sería su uso de la lengua? Los grupos se formaron, en su mayoría, con ideas comunes o formas de trabajo afines.

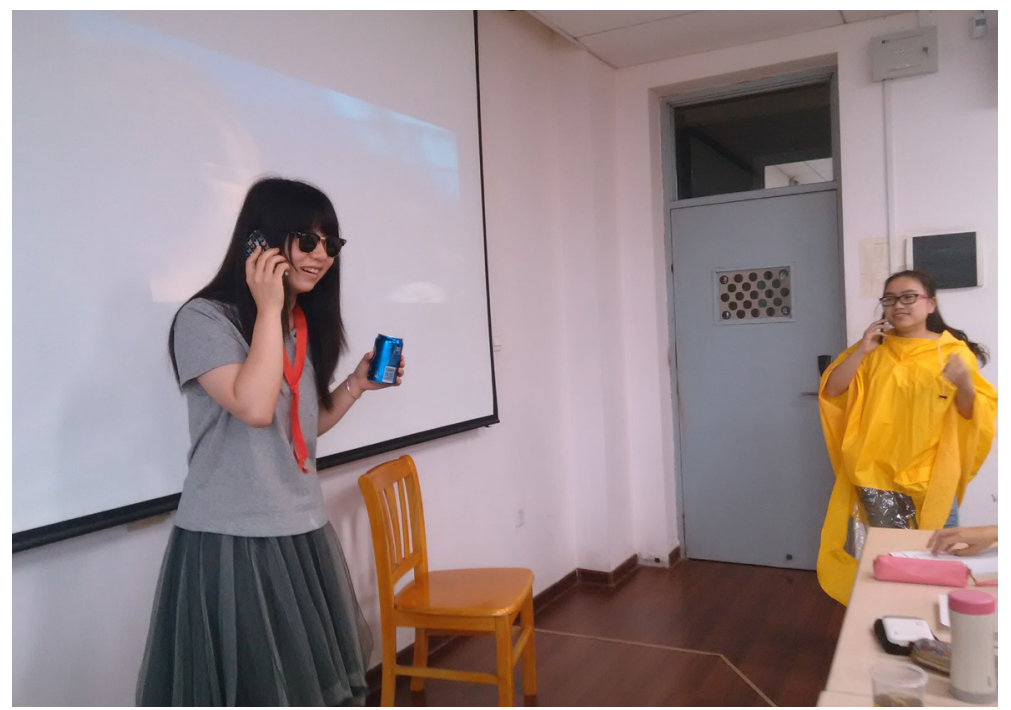

Figura 10. Tecnología y atavíos personales. Elaboración propia.

En este proyecto, con el grupo A1 se utilizó internet, cámara de vídeo, celular/ móvil, lápiz de memoria (usb), repertorios de música, archivos con diferentes sonidos (efectos especiales) y laptop/ordenador portátil. Alfonso de Toro los denomina "elementos mediales de la acción" (2014: 67), donde lo acústico y la vestimenta personal (el performance de la vida cotidiana) desempeñan un papel para la gente que hace una representación en su vida y en el teatro².

2 El autor menciona a Frida Kahlo como una pionera avant garde del arte acción, body art (de los años sesenta), arte objeto e incluso el happening Fluxus (de los años setenta). 
Además de los elementos ya enlistados, los impermeables/chubasqueros, gafas/lentes, botellas de refresco llenas o vacías, todos los accesorios pueden ser útiles en la escenificación para la clase ELE, como se observa en la Figura 10. La llamada "conversación transaccional" del Plan Curricular (Instituto Cervantes, 2006: 336) se puede implementar en tiempo real y/o con teléfonos celulares y dispositivos portátiles.

El ordenador de la clase con micrófonos integrados es de gran utilidad si se emplea como estudio de grabación en el aula. La propuesta es utilizar todo lo que esté al alcance de la mano para practicar, por ejemplo, las consonantes que presentan dificultades en su pronunciación. Al final del ejercicio, los estudiantes pueden elegir realizar otras representaciones frente a la cámara.

Con el grupo B1-B2 se decidió trabajar con formato de cortometraje o videomóvil, puesta en escena que fue realizada en dormitorios, sótanos, aulas, salidas de metro, entre otros lugares. De esta forma, el texto de Carlos Fuentes cobró nueva vida y la escultórica figura del Chac Mool tuvo mayor fuerza en el imaginario del estudiantado. La intervención de la lectura favorece la acción, y el lenguaje corporal proporciona al estudiante el acercamiento a otra cultura.

El cortometraje-escénico se realizó con un móvil/celular para su práctica; los estudiantes pudieron charlar sobre las propuestas y el resultado de las escenas filmadas en círculos de trabajo. El acto de escenificar para el aula se realizó en interiores y exteriores. Un guion favoreció en algunos casos la redacción creativa y su relación con la gramática centró los contenidos funcionales, léxicos, estratégicos y culturales y los objetivos a alcanzar, sin dejar de lado la expresión y la fluidez.

En las prácticas (como deberes/tareas que se realizaron en diferentes sitios, como el aula misma) las y los discentes lograron captar y reproducir situaciones. Sabían ya que la voz y el lenguaje corporal eran indispensables para una puesta en escena: las pulsiones y acciones realizadas con sentido no están en el cuarto de al lado, permanecen unidas, se presentan, se vivifican. Es una forma de motivación para el aprendizaje; no es un apartado extra de la asignatura, sino una fuente de experimentación para los objetivos de la clase de elE (y también una valiosa disciplina formal que les permite a los alumnos interesados adentrarse en los caminos de la dramaturgia de manera más profesional).

El nivel principiante de un estudiante no fue un obstáculo para que aprendiera la lengua a través del teatro. La intervención de otros elementos (diccionarios o dispositivos electrónicos) en la escenificación favorecía la dinámica.

El guion, el tema elegido y la dinámica con los participantes, incrementaron su confianza para hablar con un texto en la mano, una tableta, un móvil/celular, que poco a poco tendrá un papel secundario o ninguno. Aprendieron el proceso de una prueba escénica con aquellos temas que a los estudiantes les entusiasman 
(y necesitan), brindándoles certidumbre; al mismo tiempo, pudieron enfrentarse a aspectos problemáticos del sistema de la lengua como ciertas conjugaciones de verbos (Figuras 11 y 12). Las alumnas y alumnos cobraron conciencia del significado de la conjugación de un verbo: "Yo soy, yo estoy".

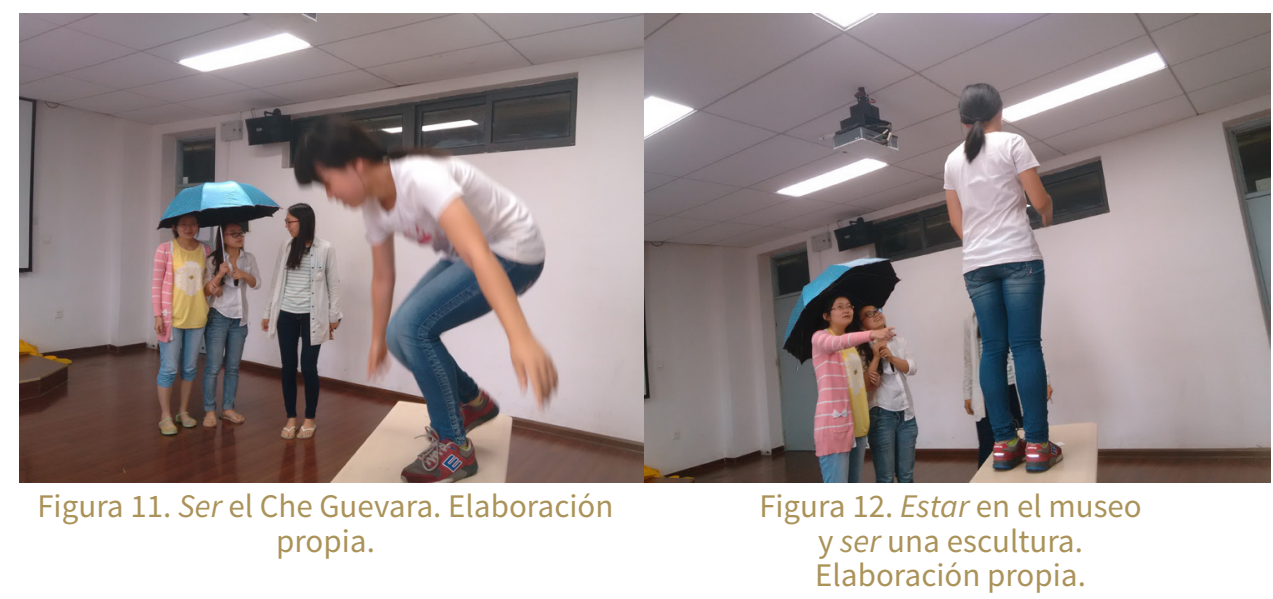

Para la recolección de datos se solicitó a cada participante una redacción sobre su experiencia. A continuación se enumeran los puntos más sobresalientes de la evaluación realizada por los estudiantes sobre la puesta en escena:

a. A pesar de la timidez inicial en algunos participantes, existió un gran entusiasmo por otras formas de aprendizaje comunicativo. Fortaleció su competencia comunicativa al cien por ciento (según sus propias palabras).

b. La mejor puntuación siempre vino de parte del estudiantado (abierto a nuevas ideas).

c. La memorización funciona (algunos profesores consideran que la repetición de información es de otra época, pero esta experiencia verifica que no es así). Algunos estudiantes, como los participantes, saben aprovecharla (los profesores de elE en países no hispanohablantes no deben olvidar que son huéspedes de otra cultura).

d. "¡Es hermoso!", dijeron las estudiantes que representaron Chac Mool (el proverbio dice que "para muestra, basta un botón". "Pero queríamos más", comentaron quienes participaron).

e. La comunicación hablada y la redacción mejoraron.

El entusiasmo que despertó este método les proporcionó una observación detallada de sus posibilidades y limitaciones, los puntos que deberían trabajar (según sus propias palabras). Aquellas, aquellos discentes habían encontrado 
el reflejo de sus propias necesidades y la representación les devolvió el entusiasmo inicial - por el cual se habían inscrito-, cuando decidieron aprender un idioma. Las/los estudiantes adquirieron mayor seguridad en sí mismas y conciencia del poco valor que le habían dado al lenguaje corporal. Con las escenificaciones se despertó la creatividad, algo que Suárez Lasierra (2013) considera como un valor. Los recursos disponibles se focalizaron en el manejo del nuevo vocabulario y marcadores discursivos. Se observó una mejora en la pronunciación, así como la necesidad de preparar al alumno en el plano semántico y con las metas educativas particulares de la programación en un nivel de lengua.

\section{CONCLUSIÓN}

A partir de las experiencias obtenidas con la puesta en escena, es posible elaborar nuevas observaciones para su uso didáctico y mejorar las intervenciones en el aula de ELE. No basta con utilizar las imágenes, fantasías y emociones; hay que desarrollarlas en una atmósfera interiorizada que permita observar las áreas de trabajo con nuevos ojos y tener la oportunidad de ampliar la exploración en el teatro o la lengua extranjera por sí misma. Los estudiantes pueden ampliar su adquisición de léxico de la lengua meta, potenciar el uso de las destrezas integradas, aprender la organización del discurso y al mismo tiempo mejorar la comunicación no verbal (paralenguaje, quinesia, proxemia, cronemia). Todo esto puede incrementar la autoestima y favorecer un clima armónico que estimule el aprendizaje sin la preocupación de cometer errores, pues se autocorregirán gracias a un contexto en el que se faciliten las tareas que promueven un aprendizaje significativo al generar actos de comunicación reales en el aula.

Los jóvenes que estaban clasificados en un nivel de competencia de A1-A2, en realidad tenían otro nivel real que permanecía oculto. La puesta en escena y el uso del espacio vacío, en los diferentes niveles de la lengua, potenciaron una plataforma de dominio del idioma utilizando cualquier lugar, convirtiéndolo en escenario para observar y aprender una cultura y su lengua, como se expuso en 2.1.

En el aprendizaje de una lengua, la combinación de la gramática pedagógica, el espacio vacío - las aulas - y la dramaturgia, es una manera realista de ver el mundo, no exenta de fantasía. Permite ver cómo y con qué elementos los juegos pueden resultar más interesantes; las noticias y los eventos deportivos que están en todos los medios de comunicación no son ajenos a los estudiantes. Una puesta en escena que les ayude a integrar estos elementos se hace cada vez 
más necesaria para dar un paso a la transculturalidad. Aprender a escucharnos es tarea de todas y todos.

\section{BIBLIOGRAFÍA}

Alonso-Cortés, M. D. (1998). La naturalidad en las conversaciones de los alumnos de E/L. En F. Moreno Fernández, M. Gil Bürmann y K. Alonso (Eds.). El español como lengua extranjera: del pasado al futuro. Actas del viii Congreso Internacional de ASELE. Universidad de Alcalá, 115-123.

Alcón Soler, E. (2002). Bases lingüísticas y metodológicas para la enseñanza de la lengua inglesa. Universitat Jaume.

Aristóteles. (1991). Poetik. M. Fuhrmann (ed.). Phillipp Reclam.

Balme, C. B. (2008). The Cambridge Introduction to The Theatre Studies. Cambridge University Press.

Batenson, G. (1972). Steps to an ecology of mind. Chandler Pub.

Berber Irabien, D. (1998). El teatro como participación viva. En F. Moreno Fernández, M. Gil Bürmann y K. Alonso (Eds.). El español como lengua extranjera: del pasado al futuro. Actas del viii Congreso Internacional de ASELE. Universidad de Alcalá, 150-157.

Brook, P. (2014). El espacio vacío. Ediciones Península.

Cano Gines, A. (1996). La autoestima: su importancia en la enseñanza de segundas lenguas. En Actas del xı Congreso Internacional de la Asociación Lingüística y Filología de América Latina. 11 (2), 1339-1345.Consejo de Europa (2002). Marco Común Europeo de Referencia para las lenguas: enseñanza, aprendizaje, evaluación. http://cvc.cervantes.es/ensenanza/biblioteca_ele/ marco/cap_09.htm.

Corral, Anna (2013). El teatro en la enseñanza de lenguas extranjeras. La dramatización como modelo y acción. Didáctica. Lengua y Literatura, 25. http://revistas.ucm.es/index.php/DIDA/article/view/42238/40212.

Crespo, I. (30 de julio de 2015 ). Sexo y redes sociales, la última frontera publicitaria. El País. http://elpais.com/elpais/2015/07/29/ estilo/1438169401_370461.html.

De Toro, A. (2014). Las 'nuevas Meninas' o 'bienvenido Foucault' 'Performance' -'Escenificación' - 'Transmedialidad' - 'Percepción'. Frida Kahlo: Diario - fotografía - Pintura. En A. de Toro y R. Ceballos (Eds.). Frida Kahlo 'revisitada'. Estrategias transmediales-transculturales transpicturales. 
Georg Olms Verlag, 67-90. https://home.uni-leipzig.de/detoro/wp-content/ uploads/2018/05/05_A.-de-TorO_DEF.pdf.

Duchamp, M. (1968). Textos 2. Era.

Ellis, R. (1997). Second Language acquisition research: How does it help teachers? English Language Teaching Journal, 47, 3-11.

Esch, K. V. (1988). La comprensión lectora del español como lengua extranjera: necesidades comunicativas, objetivos y métodos de enseñanza-aprendizaje. Monográficos marco ELE, (11), 274-303. http://marcoele.com/ descargas/ navas/13.van-esch.pdf.

Fernández Vítores, D. (2019). El español una lengua viva. Informe 2019. En Instituto Cervantes (Ed.). El español en el mundo. Anuario del Instituto Cervantes, pp. 15-105.

Fleming, M. y Byram, M. (2001). Perspectivas interculturales en el aprendizaje de idiomas. Enfoques a través del teatro y la etnografía. Cambridge University Press.

Gardner, H. (2006). Multiple Intelligences. New Horizons. Basic Books.

Hui-Chuan, L. (1998). El uso del artículo en el español: errores e implicaciones pedagógicas. En F. Moreno Fernández, M. Gil Bürmann y K. Alonso (Eds.). La enseñanza del español como lengua extranjera: del pasado al futuro. Actas del VIII Congreso Internacional de ASELE, pp. 519-525.

Instituto Cervantes (Ed.) (2019). El español en el mundo. Anuario del Instituto Cervantes. Instituto Cervantes, Bala Perdida.

Jackson, A. y Vine, C. (Eds) (2013). Learning through Theatre. The Changing Face of Theatre in Education. Routledge.

Jenson, M. y Hermer, A. (2001). El aprendizaje a través del juego: aprendizaje de lenguas extranjeras mediante los sentidos. En M. Fleming y M. Byram (Eds.). Perspectivas interculturales en el aprendizaje de idiomas. Enfoques a través del teatro y la etnografía. Cambridge University Press. 183-195.

Maley, A. y Duff, A. (1982). Drama Techniques in Language Learning. Cambridge University Press.

Maler, T. (Ed) (1879). Chac Mool, Ilustración. Braunschweig. http://resolver.iai. spk-berlin.de/IAl00006A6E00000000

Morgan, C. (2001). Encuentros interculturales. En M. Fleming y M. Byram (Eds.). Perspectivas interculturales en el aprendizaje de idiomas Enfoques a través del teatro y la etnografía. Cambridge University Press, 225-241.

Nißl, S. (2011). Die Sprachenfrage in der Europäischen Union. Moglichkeiten und Grenzen einer Sprachenpolitik für Europa. Herbert Utz Verlag. 
Orihuela, J. L. (2011). La auténtica gramática de la Web. Revista Mexicana de Comunicación. 13 (126), 21-23.

Paz, O. (1968). Marcel Duchamp o el castillo de la pureza. Era.

Plan Curricular del Instituto Cervantes (2006). Niveles de referencia para el español A - A2. Editorial Biblioteca Nueva.

Plan Curricular del Instituto Cervantes (2006). Niveles de referencia para el español B1-B2. Editorial Biblioteca Nueva.

Risager, K. (2001). La enseñanza de idiomas y el proceso de la integración europea. En M. Byrann y M. Fleming (Eds.). Perspectivas interculturales en el aprendizaje de idiomas. Enfoques a través del teatro y la etnografía. Cambridge University Press, 242-253.

Sarlo, B. (1994). Escenas de la vida posmoderna. Espasa Calpe, Ariel.

Suárez Lasierra, M. (2013). Actividades creativas de la gramática: Gramática y creatividad: ¿Una contradicción? Hispanorama, 140, 74-76.

Schewe, M. (1993). Fremdsprache inszenieren. Zur Fundierung einer dramapädago-gischen Lehr- und Lernpraxis. Carl Ossietzky Universität.

VanPatten, B. (2002). From Input to Output. A Teacher's Guide to Second Language Acquisition. McGraw Hill.

Vargas, E. (2011). ¿Sirve Twitter para hacer periodismo? ¿Qué puedo decir con 140 caracteres? Revista Mexicana de Comunicación, 23 (126), 12-13.

Villegas, J. (2009). Tendencias pictóricas y teatro: tenebrismo y primitivismo en la puesta en escena contemporánea. En A. de Toro (Ed.). Dispositivos espectaculares latinoamericanos: Nuevas hibridacionesTransmedializaciones-Cuerpo. Georg Olms Verlag, 11-25. 